OPEN ACCESS

Edited by:

Clelia Madeddu,

University of Cagliari, Italy

Reviewed by:

Nada Benajiba,

Princess Nourah Bint Abdulrahman

University, Saudi Arabia

Maria Marino,

Roma Tre University, Italy

*Correspondence:

Leigh A. Neumayer

leigh.neumayer@jax.ufl.edu

Specialty section:

This article was submitted to

Clinical Nutrition,

a section of the journal

Frontiers in Nutrition

Received: 08 July 2020

Accepted: 15 October 2020

Published: 19 November 2020

Citation:

Stillwater BJ, Bull AC, Romagnolo DF, Neumayer LA, Donovan MG and Selmin Ol (2020) Bisphenols and Risk of Breast Cancer: A Narrative Review of the Impact of Diet and Bioactive

Food Components.

Front. Nutr. 7:581388.

doi: 10.3389/fnut.2020.581388

\section{Bisphenols and Risk of Breast Cancer: A Narrative Review of the Impact of Diet and Bioactive Food Components}

\author{
Barbara J. Stillwater ${ }^{1}$, Ashleigh C. Bull ${ }^{2}$, Donato F. Romagnolo ${ }^{3,4}$, Leigh A. Neumayer ${ }^{5 *}$, \\ Micah G. Donovan ${ }^{3,4}$ and Ornella I. Selmin ${ }^{3,4}$ \\ ${ }^{1}$ Department of Surgery, Breast Surgical Oncology, University of Arizona, Tucson, AZ, United States, ${ }^{2}$ School of Medicine, \\ University of Utah, Salt Lake City, UT, United States, ${ }^{3}$ Department of Nutritional Sciences, University of Arizona, Tucson, AZ, \\ United States, ${ }^{4}$ University of Arizona Cancer Center, Tucson, AZ, United States, ${ }^{5}$ Department of Surgery, University of Florida \\ College of Medicine-Jacksonville, Jacksonville, FL, United States
}

Data from preclinical studies suggest a link between increased risk of breast cancer and exposure to bisphenols at doses below what the United States Food and Drug Administration (FDA) considers as safe for consumption. Bisphenols exert estrogenic effects and are found in canned and plastic wrapped foods, food packaging, and plasticware. Mechanistically, bisphenols bind to the estrogen receptor (ER) and activate the expression of genes associated with cell proliferation and breast cancer. In this paper, we present a narrative literature review addressing bisphenol $A$ and chemical analogs including bisphenol $A F$, bisphenol $F$, and bisphenol $S$ selected as prototype xenoestrogens; then, we discuss biological mechanisms of action of these bisphenols in breast cells and potential impact of exposure at different stages of development (i.e., perinatal, peripubertal, and adult). Finally, we summarize studies detailing interactions, both preventative and promoting, of bisphenols with food components on breast cancer risk. We conclude the review with a discussion of current controversies in interpretation of the above research and future areas for investigation, including the impact of bisphenols and food components on breast tumor risk.

Keywords: breast cancer, epigenetics, nutrition, bisphenol, estrogen receptor (ER)

\section{INTRODUCTION}

Through the environment and foods, women are exposed to xenobiotics, which can exert exogenous endocrine effects on the body. These endocrine disruptors that exert estrogen (E2)-like effects may influence breast cancer risk, and include polychlorinated biphenyls, pesticides, and plastic additives. One such plastic additive is bisphenol A (BPA), which shares chemical similarities with other bisphenols such as bisphenol AF (BPAF), bisphenol F (BPF), and bisphenol-S (BPS) (Figure 1A). Bisphenol A (BPA) is an industrial chemical primarily used in the production of polycarbonate plastics and epoxy resins (1). Polycarbonate plastics are used in water bottles, toys, $\mathrm{CDs}$, food and beverage packaging, plastic tableware, flame retardants, medical, dental, optical devices, computers, wire insulation, and thermal paper (2-4). Epoxy resins are used as lacquers to coat metal products like food cans, bottle tops, and water supply pipes $(2,3)$. BPA is also found in dust, laminate flooring, paints, and home electronics (2). Classified as endocrine disrupting 


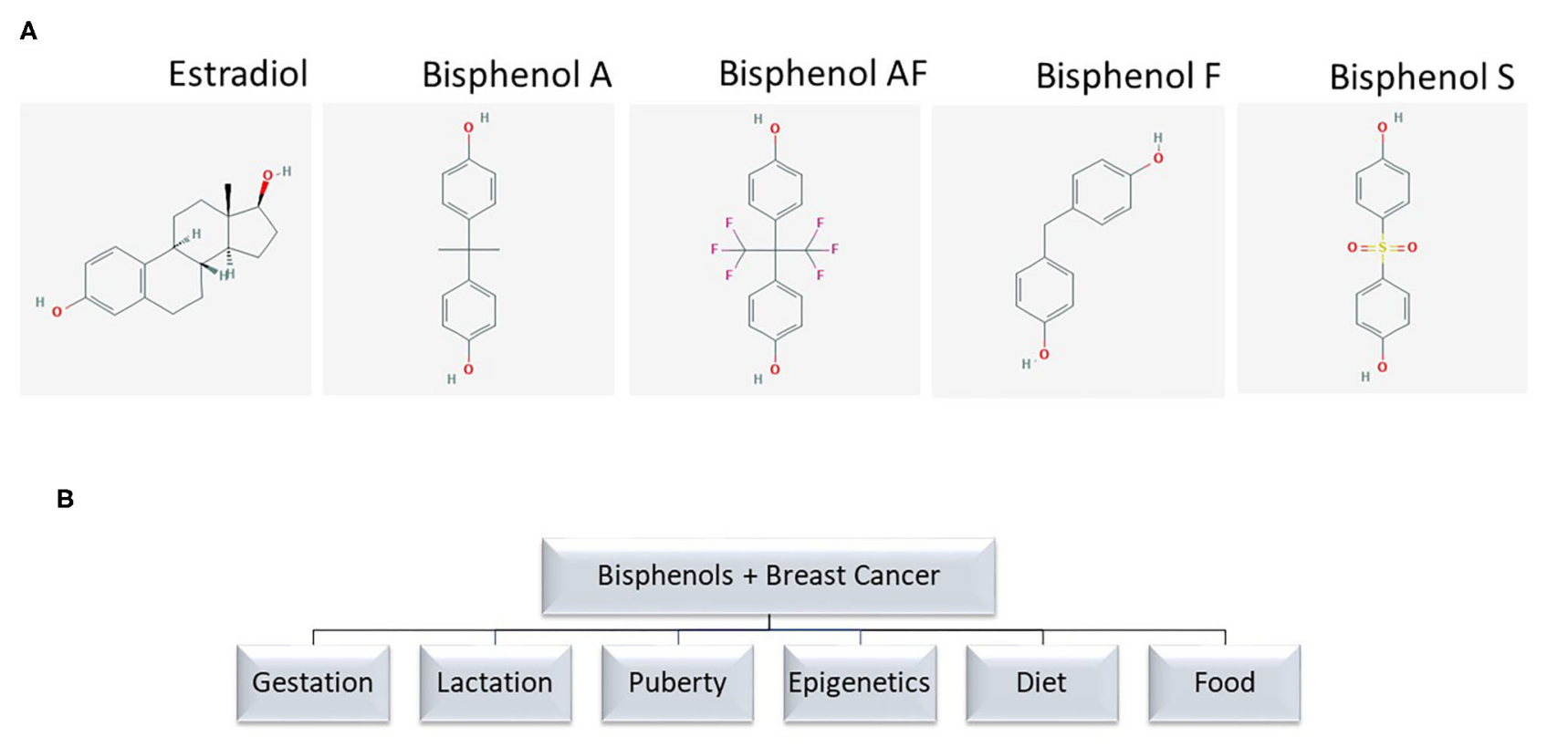

FIGURE 1 | (A) Chemical structure of bisphenol analogs. Chemical structures are from PubChem. (B) Terms used for PubMed search.

chemicals (EDC) due to their structural similarity to E2, bisphenols can interfere with normal endocrine functions depending on dose and timing of exposure throughout life. Studies have examined the biological effects of exposure to bisphenols during various stages of life such as gestation, lactation, and puberty, and as causative agents in the development of endocrine tumors, especially of the breast. Breast cancer is the most common cancer in women aside from skin cancers, and $12 \%$ of women in the United States will receive this diagnosis in their lifetime. Breast cancer has three major clinical subtypes that matter to clinicians, patients and families alike: $70 \%$ of breast cancers are hormone (estrogen and progesterone) receptor positive, $15-20 \%$ are human epidermal growth factor (ERBB2) positive (formerly HER2), and 15\% are "triple negative" or do not possess receptors for homones or ERBB2 (5). These clinical subtypes determine treatment and prognosis in most cases of breast cancer. BPA, as an EDC, has been studied as a causal agent in these cancer subtypes with varying effects depending on the dosage and clinical subtype.

The objectives of this review are (1) to summarize recent original research evidence form preclinical and clinical studies related to biological mechanisms of bisphenol interference with regulation of endocrine functions in the breast; and (2) discuss biological interactions of food components with bisphenols and their impact on breast cancer risk.

\section{METHODOLOGY}

We searched PubMed to identify relevant studies published in English on the relationships between BPA and BPS exposure and breast cancer cross-checked with references for selected search terms (Figure 1B). Reviews and original research published before 2010 are excluded here except to direct the reader to two significant studies related to mechanisms of action or human exposure to bisphenols linked to breast cancer.

\section{RESULTS}

\section{Sources of Exposure}

Food packaging represents the major source of human exposure to bisphenols. A list of foods containing bisphenols and relative concentrations is provided in Table 1 (6-9). The hydrolysis of the ester bonds that link bisphenol monomers is accelerated by heat, as well as acids and bases (2). As the monomers are freed, they are leached from the plastic packaging into products, especially food and water. Because hydrolysis occurs with processes essential to food preparation, transport, and storage, bisphenols are found ubiquitously in human diet.

Canned foods are a significant source of dietary exposure. Exposure to BPA from daily use of plastic water bottles is $\sim 0.17$ $\mu \mathrm{g} / \mathrm{d}$, and from food cans $\sim 20 \mu \mathrm{g} / \mathrm{can}(10)$. About $70 \%$ of canned fruit and vegetables samples have a BPA content in the range of $0.8 \mathrm{ng} / \mathrm{g}$ for V8 juice to up to $790 \mathrm{ng} / \mathrm{g}$ (canned refried beans), with the second and third highest levels as high as $730 \mathrm{ng} / \mathrm{g}$ in canned green beans and as high as $310 \mathrm{ng} / \mathrm{g}$ for canned green peas. Mean BPA levels in canned fish average $7-12 \mathrm{ng} / \mathrm{g}$ in the US $(6,11) ; 33 \mathrm{ng} / \mathrm{g}$ in Europe (12); and $106 \mathrm{ng} / \mathrm{g}$ in Canada (13). The estimated total adult exposure to BPA from food ranges from 30 to $70 \mathrm{ng} / \mathrm{kg} / \mathrm{d}(14)$.

While metal does not typically contain bisphenols, food cans are lined with epoxy resins, which contain bisphenols (e.g., BPA) in order to provide a malleable structure to the plastic lining. 
TABLE 1 | Bisphenol concentrations found in foods.

\begin{tabular}{|c|c|c|}
\hline \multirow[t]{2}{*}{ Foods } & \multirow{2}{*}{$\begin{array}{c}\text { Mean or range } \\
\text { BPA level } \\
\text { ng/gm }\end{array}$} & \multirow{2}{*}{$\begin{array}{c}\text { Mean } \\
\text { BPS level } \\
\text { ng/gm }\end{array}$} \\
\hline & & \\
\hline \multicolumn{3}{|l|}{ Canned Foods } \\
\hline Refried beans* & $6.3-790$ & 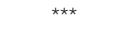 \\
\hline Green beans ${ }^{\star}$ & $22-730$ & 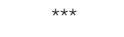 \\
\hline Green beans ${ }^{\star}$ & 18.0 & ND \\
\hline Green peas ${ }^{\star}$ & $3.1-310$ & 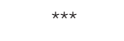 \\
\hline Green peas ${ }^{\star}$ & 30.0 & ND \\
\hline Del monte fresh cut green beans & $26.6-65.0$ & $\star \star \star *$ \\
\hline Creamed soup* & 41.0 & ND \\
\hline Portuguese canned mackerel & 36.3 & $* \star *$ \\
\hline Baked beans* & 36.0 & ND \\
\hline Progresso light homestyle vegetable and rice soup & $15.6-22.7$ & 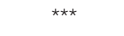 \\
\hline Meat broth* & 23.0 & ND \\
\hline Portuguese canned tuna & 17.7 & 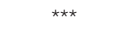 \\
\hline Progresso classics vegetable soup & $7.3-11.7$ & 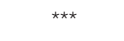 \\
\hline Evaporated millk* & 11.0 & ND \\
\hline Progresso classics tomato basil soup & $8.2-10.7$ & 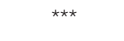 \\
\hline Campbell's condensed chicken noodle soup & $4.5-7.1$ & 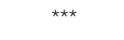 \\
\hline Hormel chili with beans & $3.5-5.6$ & 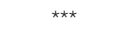 \\
\hline Kroger sweet peas & $2.7-4.0$ & $\star \star \star ~$ \\
\hline Chicken of the sea chunk light tuna in water & $1.7-3.8$ & 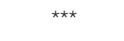 \\
\hline Kroger mixed vegetables & $2.3-4.2$ & 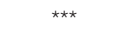 \\
\hline Campbell's chunky savory pot roast & $1.5-2.0$ & 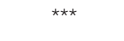 \\
\hline Kroger canned beef & $0.8-1.7$ & $\star \star \star ~$ \\
\hline Enfamil premium LIPIL infant formula milk based & $1.0-1.2$ & 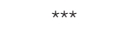 \\
\hline Beach cliff sardines in water & $0.8-1.3$ & 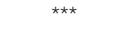 \\
\hline V8 100\% vegetable juice & $0.7-0.8$ & $\star \star \star$ \\
\hline Hormel spam & $<0.2-0.3$ & 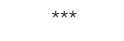 \\
\hline Similac advanced infant formula & $<0.2$ & *** \\
\hline Chef boyardee mac and cheese & $<0.2$ & *** \\
\hline \multirow[t]{2}{*}{ Bumble bee chunk light tuna in water } & $<0.2$ & 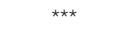 \\
\hline & & 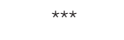 \\
\hline Plastic Wrapped Foods & & 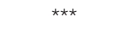 \\
\hline Chef boyardee spaghetti and meatballs & $4.3-5.0$ & *** \\
\hline Sliced turkey ${ }^{*}$ & 0.35 & *** \\
\hline Sliced chicken breast* & $<0.2$ & 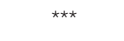 \\
\hline Sprouts organic cinnamon applesauce & $<0.2$ & 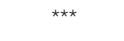 \\
\hline \multicolumn{3}{|l|}{ Unpackaged and Non-Canned Foods } \\
\hline Ground beef* & ND & 35.0 \\
\hline Beef steak ${ }^{\star}$ & ND & 18.0 \\
\hline Organ meats* & ND & 7.6 \\
\hline Roast beef* & ND & 7.1 \\
\hline Veal cutlets* & ND & 6.9 \\
\hline Pork ${ }^{*}$ & ND & 5.1 \\
\hline Sausages* & ND & 3.3 \\
\hline Cold cuts* & ND & 2.7 \\
\hline 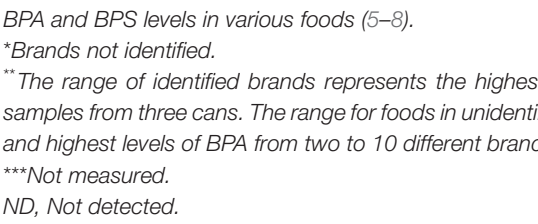 & $\begin{array}{l}\text { st and lowest levels } \\
\text { ified brands represent } \\
\text { ds of the same food. }\end{array}$ & $\begin{array}{l}\text { of BPA from } \\
\text { ts the lowest }\end{array}$ \\
\hline
\end{tabular}

Monomers of BPA are known to leach into contained food through heat used for sterilization or food preparation $(2,15)$. Similar to epoxy resins, leaching from polycarbonate plastics is increased if the container is heated. If polycarbonate plastic is used in packaging such as water bottles, food cans, infant bottles, or formula cans, heating is likely to increase human bisphenol exposure from the food.

The relationship between the type of packaging and the amount of detectable BPA and/or BPS is demonstrated in the table (Table 1). The amount of BPA in canned and plastic wrapped foods varies widely by manufacturer and their canning processes. In this table, the presence of BPS appears to be limited to unpackaged foods.

\section{Governmental Regulation of BPA}

Since 2012, the FDA has banned BPA from use in plastic baby bottles, sippy cups, and baby formula packaging (1). However, based on scientific review, the FDA, as of 2018, has "not found any information to prompt a revision of FDA's safety assessment of BPA in food packaging" (16). Therefore, its use continues in non-infant applications such as food packaging.

BPA is classified by the US Environmental Protection Agency as an endocrine disrupting chemical (EDC). The US Environmental Protection Agency (USEPA) has set an oral Reference Dose (RfD) for BPA at $50 \mu \mathrm{g} / \mathrm{kg}$ bw/day (17). The RfD is defined as an estimate of daily oral exposure that is likely to be without significant risk of negative lifetime effects. However, this recommendation only takes into account daily oral intake, and does not address potential exposure in utero or as an infant, exposure from environmental hazards, or accumulated stores in adipose tissue that are gradually released over time (18). The USEPA plans to gather data with respect to environmental effects of BPA to further determine whether "BPA either does or does not present an unreasonable risk of injury to the environment" (19). In 2016, the European Chemicals agency identified BPA as a substance of very high concern regarding its use in thermal paper and thus BPA was added to REACH Annex XVII Restricted Substances List. This new entry bans BPA's use in thermal paper with a concentration equal to or above $0.02 \%$ by weight (20).

\section{Mechanisms of Action}

BPA was first synthesized in 1891 by Russian chemist Alexander Dianin. However, its estrogenic properties were not recognized until 1932 by British chemist, Charles Dodds. In 1934, Dodds compounded a more stable form of synthetic estrogen, showing that a synthetic estrogen could mimic natural estrogen in animals. He later went on to synthesize diethylstilbestrol or DES, an artificial estrogen that is a structurally similar to BPA. In 1971, DES was banned for use during pregnancy in the US due to increased risk of endometrial and other cancers in female fetuses. However, DES was still used as a contraceptive and as a treatment for post-partum lactation suppression. Although studies of DES in the 1970's linked DES exposure to cancers of the female lower genital tract, it was not until 1985 that the FDA listed DES as a known carcinogen (21).

Excellent reviews of biochemical mechanisms of actions of BPA are available elsewhere (22). Due to structural similarity to 
estradiol (Figure 1A), bisphenols act through a genomic mode of action via binding to the estrogen receptors $\operatorname{ER} \alpha$ and $\operatorname{ER} \beta$ (23), though bisphenols have lower affinity for these receptors than naturally synthesized human estrogens. For example, compared to the activity induced by $1 \mathrm{nM} 17-\beta$-estradiol (E2), a $50 \%$ activation of $\mathrm{ER} \alpha$ requires a concentration of BPA approaching $\sim 1.3 \mu \mathrm{M}$, raising the question as to whether or not micromolar concentrations of BPA and other bisphenols are achievable in humans through chronic or acute exposure (24).

Studies have shown that in the MCF-7 breast cancer cell line, BPA binds with similar affinities to $\mathrm{ER} \alpha(\mathrm{IC} 50 \sim 6.0 \times 10-6 \mathrm{M})$ and $\operatorname{ER} \beta$ (IC50 $6.5 \times 10-6 \mathrm{M}$ ); elevates transcriptional activity at estrogen response elements; and exerts proliferative effects (25). The MCF-7 cell line has been shown to express both ER $\alpha$ and ER $\beta$ (26). Although ER $\beta$ has been suggested as a cancer therapeutic target (27), some studies (28) show that when ER $\alpha / \beta$ positive MCF-7 cells are treated with an active metabolite of BPA [4-methyl-2,4-bis(4-hydroxyphenyl)pent-1-ene (MBP)] at levels $(\sim 1 \mathrm{nM})$ comparable to human environmental exposure, $\mathrm{ER} \alpha$ protein expression is downregulated and proliferation is increased via ER $\beta$. In particular, the MCF-7 proliferation stimulated by MBP is dose-dependently counteracted by the cotreatment with the selective ER $\beta$ antagonist PHTPP (4-[2phenyl-5,7-bis (trifluoromethyl) pyrazolo [1,5-a]-pyrimidin-3$\mathrm{yl}$ ] phenol). Additional support for a positive role of ERs in the BPA-induced proliferation is offered by another study showing that in MCF-7 cells, BPA transactivates both ER $\alpha$ and ER $\beta$ (29). This cumulative evidence suggests that parent bisphenol compounds and metabolites may exert proliferative effects on breast cells at physiologically relevant $(<1.0 \mathrm{nM})$ concentrations.

In addition to binding to nuclear ER, bisphenols activate signaling pathways through non-genomic mechanisms. In ER $\alpha-$ positive (30) and triple-negative breast cancer (TNBC) cells (MDA-MB-231) (31), BPA activates signal transduction pathways [i.e., extracellular signal-regulated kinase 1/2 (ERK1/2)] involved in proliferation via G-protein coupled estrogen receptor (GPER) and epidermal growth factor receptor (EGFR). Using pharmacological inhibition and gene-silencing approaches, studies by Pupo et al. (32) document that BPA induces in SkBr-3 breast cancer cells the expression of the GPER-target genes cFOS, early-growth response protein 1 (EGR-1), and connective tissue growth factor (CTGF) through the GPER/EGFR/ERK signal transduction pathway. Via GPER, BPA induces cell proliferation and migration of TNBC cells ( $\mathrm{SkBr}-3$ and MDAMB-231) and enhances tumor growth in vivo (31). In hypoxic conditions, BPA promotes hypoxia inducible factor-1-alpha (HIF-1 $\alpha)$ and VEGF expressions through a GPER/Caveolin$1 /$ heat shock protein 90 axis (33). Interestingly, ER $\alpha$ is activated and degraded by hypoxia in breast cancer cells. Conversely, BPA enhances ER $\alpha$-mediated transcriptional activity under conditions of hypoxia. Since hypoxia is known to favor tumor progression, exposure to BPA and other bisphenols exacerbates resistance to endocrine therapy via GPER-dependent mechanisms (24). Low levels of BPA $\left(\leq 10^{-8} \mathrm{M}\right)$ induce phosphorylation of protein kinase D1 (PKD1), which is associated with increased activation state of PKD1 (34). These observations suggest that exposure to bisphenols at physiologically relevant concentrations induce the growth of ER-positive and ER-negative breast cancer cells through genomic and non-genomic mechanisms. The following sections summarize research evidence related to effects of bisphenols on endpoints of breast cancer from preclinical and clinical studies. While most studies have focused on BPA, when available comparative data about its analogs BPAF, BPF, and BPS are included.

\section{Cell Culture BPA}

In ER $\alpha$-positive breast cancer cells (MCF-7, T47D), BPA increases expression of $\mathrm{p} 53$ and $\mathrm{ER} \alpha$ in a concentrationdependent manner. It also promotes cell proliferation which is hampered by the ER $\alpha$-antagonists tamoxifen and ICI (35). BPA supports the growth of ER $\alpha$-positive tumors by inducing heat shock factor-1 (HSF1) phosphorylation on S326 via mitogenactivated protein kinase (MAPK)/ERK1/2 (MEK1/2) signaling (36). BPA, along with other endocrine-disrupting compounds, increases aromatase expression and activity leading to increased levels of $17 \beta$-estradiol and proliferation in ER $\alpha$-positive breast cells (37). BPA and 4-cumylphenol (4-CP), another E-like compound, at levels ranging from $10^{-9}$ to $10^{-5} \mathrm{M}$, stimulate cell proliferation and expression of $\mathrm{ER} \alpha, \mathrm{pS} 2$, and B-cell lymphoma-2 (Bcl-2) in MCF-7 breast cancer cells. In addition to exerting E2like effects, studies with ER-positive breast cancer cells show BPA antagonizes the proapoptotic effects of tamoxifen while favoring transition of cell cycle from G1 to $S$ phase, and upregulating cyclin D1 (CCND1) and ER $\alpha$. Expression of estrogen related receptor y $(\mathrm{ERR} \gamma)$ and its coactivators peroxisome proliferationactivated receptor $\gamma$ coactivator- $1 \alpha$ (PGC- $1 \alpha)$ and PGC- $1 \beta$ are also increased. In turn, binding of ERR-y to BPA protects the latter from deactivation via 4-hydoxytamoxifen (2).

These data support the notion that exposure to BPA and possibly other bisphenols increases proliferation while hampering the efficacy of endocrine therapies (38). In MCF7 cells exposed to nanomolar concentrations $(10 \mathrm{nM})$ of BPA there is accumulation of aldehyde dehydrogenase 1 (ALDH1), a marker of human mammary stem cells, and increased growth of mammospheres. These effects are not observed in ER-negative (MDA-MB-231) breast cancer cells. Mechanistically, BPA induces expression of SRY-related HMG box-containing transcription factor-2 (SOX2), a factor that promotes cell proliferation and metastasis. These findings denote that physiologically relevant levels of BPA increase growth of ER-positive breast cancer through stem-like cell activity via upregulation of SOX2, which participates among other factors [e.g., octamer-binding transcription factor-4 (OCT4)] in the maintenance of pluripotency of breast stem cells and an undifferentiated cellular state (39).

Endogenous estrogens and bisphenols from the environment exert overlapping effects. Results of association studies with E2 and BPA $(\sim 200 \mathrm{nM})$ indicate synergistic rather than additive activating effects on $\mathrm{ER} \alpha$, phosphatidylinositol-4,5bisphosphate 3-kinase catalytic subunit alpha (PIK3CA), GPER, and phosphatase and tensin homolog (PTEN); and antagonizing effects on protein kinase B (Akt1) in breast cancer MCF-7 cells. 
Similarly, the co-exposure of lower concentrations BPA and 4-CP significantly induce cell proliferation in a synergistic fashion. Therefore, the combined effects and not simply individual exposures need to be considered to develop accurate models of breast cancer risk associated with exposure to bisphenols $(40,41)$.

Bisphenols exert biological effects based on breast cancer subtype. For example, subsequent to exposure to BPA $\left(10^{-8} \mathrm{M}\right)$, high expression of interleukin-19 (IL19), carbonic anhydrase-9 (CA9) and secreted protein acidic and rich in cysteine (SPARC) is seen in MCF-7, SK-BR3, and MDA-MB-231 cells, respectively. These gene expression signatures are believed to predict poor overall survival in luminal A, epidermal growth factor receptor2 (HER2)-enriched and TNBC patients, respectively (42). The IL-19 protein promotes proliferation and metastasis in breast cancer cells (43). CA9 catalyzes the hydration of carbon dioxide to carbonic acid and is expressed mainly in high-grade, steroid receptor negative/HER2 enriched tumors. Its role in breast tumorigenesis is attributed to reducing pericellular $\mathrm{pH}$ in response to hypoxia, thus aiding in the degradation of extracellular matrix. These biological effects may contribute to lack of response to traditional therapy by breast tumors expressing high levels of CA9. Expression of SPARC is associated with invasion and is characteristic of more aggressive phenotypes (i.e., TNBC) (44). These expression results point to differential effects of BPA on processes associated with breast cancer including impaired immune response, and enhanced invasion and metastasis.

Inflammation is a process induced by BPA, which triggers cyclooxygenase-2 (COX-2) expression via nuclear translocation of nuclear factor kappa-light-chain-enhancer of activated B cells $(\mathrm{NF}-\kappa \mathrm{B})$ and activation of MAPK/ERK1/2 in TNBC (MDAMB-231) cells (45). Overexpression of EGFR/HER2 along with ER negativity is common in inflammatory breast tumors. BPA increases EGFR/ERK signaling, culminating with increased expression of superoxide dismutase 1 (SOD1) and anti-apoptotic Bcl-2, key markers of antioxidant and anti-apoptotic processes, respectively. BPA potentiates clonogenic growth and tumor spheroid formation which are pathological characteristics of inflammatory breast tumors. Furthermore, BPA antagonizes the effects of EGFR inhibitors (46).

Exposure to bisphenols impinges on the process of invasion and metastasis via induction of matrix metalloproteinases (MMP), which are enzymes involved in degradation of extracellular matrix. In TNBC cells, BPA induces ERR $\gamma$ expression, whose knock-down markedly attenuates BPAinduced expression of MMP-2 and MMP-9. Inhibitors of ERK1/2 (PD98059) and Akt (LY294002) attenuate BPA-induced ERR $\gamma$ expression and cell invasion (47). BPA promotes migration, invasion, and an increase in the number of focal contacts. Finally, BPA induces an increase in activator protein-1 (AP-1)- and NFKB-DNA binding activity (48). Nanomolar concentrations of BPA promote in vitro migration and induce epithelial to mesenchymal transition (EMT) of ER-negative breast cancer cells associated with downregulation of fork head box A1 (FOXA1), which is a determinant of response to endocrine therapy. Further, BPA $\left(10^{-8} \mathrm{M}\right)$ significantly increases the phosphorylation of ERK1/2, p38-MAPK, and Akt in TNBC cells. Overall, these observations point to BPA as a promoter of EMT in ER-negative breast tumors (49).

\section{BPA Analogs}

Although some BPA is being replaced in industrial production, there remain concerns about similar or even more potent estrogenic effects of bisphenol analogs (3). BPS, which is absorbed directly through the skin, is found in thermal receipts and currency bills from 21 countries (50). In reference to the relative estrogenic activity of BPA substitute, BPAF is the most potent bisphenol, followed by $\mathrm{BPB}>\mathrm{BPZ} \sim \mathrm{BPA}>\mathrm{BPF} \sim \mathrm{BPAP}>$ BPS. The addition of ICI 182,780 antagonizes the activation of ER by BPA analogs. Transcriptome alterations resulting from exposure to BPA substitutes indicated that BPA analogs act as $\mathrm{ER} \alpha$ agonists in MCF-7 breast cancer cells. These results support the concern that BPA alternatives are not necessarily less estrogenic than BPA in human ER $\alpha$-positive breast cancer cells. In fact, BPAF, BPB, and BPZ may be even more estrogenic than BPA (51). At concentrations ranging from 0.1 to $10 \mu \mathrm{M}$, BPA, BPS, and BPF stimulate proliferation of MCF-7 clonal variant $(\mathrm{MCF}-7 \mathrm{CV})$ cells in the order $\mathrm{BPA}=\mathrm{BPS}>\mathrm{BPF}$. These bisphenols are equally effective at inducing the expression of CCND1 and CCNE1, and induce migration and expression of $\mathrm{N}$-cadherin (N-Cad), while reducing levels of E-caherin (E-Cad). Conversely, these responses are antagonized by the cotreatment with the ER-antagonist ICI 182,780. Thus, not only BPA but also BPS and BPF effectively activate pathways associated with breast cancer via ER-dependent mechanisms raising concerns that substitution of BPA in food packaging with these bisphenol analogs may not limit breast cancer risk (52). The treatment in culture $(24 \mathrm{~h})$ with BPA, BPF, and BPS increases (2-3 folds) the expression and activity of telomerase in MCF-7 (ER $\alpha$-positive) but not in MDA-MB-231 (ER $\alpha$-negative) cells, and this increase is prevented by cotreatment with $\mathrm{ER} \alpha$ antagonists. These results suggest that the effects of bisphenols in ER-positive breast carcinoma are mediated at least in part by telomerase, whose increased expression associates with breast cancer development and progression (53).

In MCF-7 and T47D ER+ breast cancer cells, BPAF promotes cell growth concurrently with induced ER $\alpha$ transcriptional activity and amphyregulin (AREG) (54). $\mathrm{BPF}$ at low concentration $(10 \mathrm{nM})$ significantly enhances in MCF-7 cells the protein expression of ER $\alpha$, GPER, c-Myc, and CCND1, as well as phosphorylation levels of Akt, ERK, and proliferation (55). BPAF at $0.001-1 \mu \mathrm{M}$ and BPF at $0.01-1 \mu \mathrm{M}$ increase cell viability, DNA damage and ROS in MCF-7 cells. These biological effects are attenuated by the ROS scavenger $\mathrm{N}$-acetylcysteine (NAC), indicating that ROS play a key role in the observed biological effects of BPAF and BPF on MCF-7 cells (56). BPF promotes in vitro proliferation of ER $\alpha$-positive breast cancer cells (T47D) in a dose-dependent manner, with $\mathrm{EC}_{50} \sim 120 \mathrm{nM}$. The C-X-C chemokine ligand 12 (CXCL12) is up-regulated through $\mathrm{ER} \alpha$ in T47D cells treated with BPF (57). $\mathrm{BPF}$ functions as a stimulator of $\mathrm{ER} \beta 1$ (and $\mathrm{ER} \alpha$ ) transiently expressed in MDA-MB-231 and SK-BR-3 breast cancer cells $\left(\mathrm{EC}_{50}\right.$ values for $\mathrm{ER} \beta$ : 6.87 and $2.58 \mathrm{nM}$, respectively, and $\mathrm{EC}_{50}$ values for $\mathrm{ER} \alpha$ : 24.7 and $181 \mathrm{nM}$, respectively) (58). 
In MCF-7 breast cancer cells, BPS $(10 \mu \mathrm{M})$ promotes cellular responses commonly elicited by estrogens. These include accelerated $G_{1}$ to $S$ phase transition through the cell cycle; increased CCND1 expression and phospho-retinoblastoma (p-Rb) levels; release of E2F transcription factor; and increased expression of CCNE2 and CCNA2. The BPS-induced Rb phosphorylation and cell cycle progression is antagonized by the cotreatment with the ER $\alpha$ inhibitor ICI 182,780 and cyclindependent kinase-4/6 (CDK4/CDK6) inhibitor PD 0332991 (59). In non-tumorigenic breast cells, BPS induces upregulation of EGFR, and increases proliferation (60). BPA and BPS are equipotent in disrupting the organization of the acinar structures, despite BPS being less estrogenic compared to BPA. In combination, BPA and BPS augment the capacity for non-tumorigenic breast cells to invade the lumen. These data suggest BPA and its BPS substitute affect mammary development and contribute to breast cancer development (61). Bisphenol S promotes the migration of TNBC cells in vitro through activation of YAP, a key effector of the Hippo pathway, by inhibiting its phosphorylation, which promotes YAP nuclear accumulation and up-regulation of its downstream genes such as CTGF and ANKRD1 (62).

\section{Animal Models Including Xenografts}

In a xenograft study of DCIS (ductal cancer in situ), Kim et al. documented that exposure to an environmentally humanrelevant low dose of BPA $(2.5 \mu \mathrm{g} / \mathrm{l}$ BPA for 70 days via drinking water) yields a 2 -fold increase in the growth rate of the primary tumor along with increased lymph node metastasis (63). Overexpression of PKD1 increase the growth of BPAexposed breast tumor xenografts in vivo (34). Similar to E2, BPA (37.5 mg pellet/60-days release) promotes established tumor growth of MCF-7 human breast cancer cells subcutaneously injected into flanks of ovariectomized NCR nu/nu female mice (64).

The exposure in utero [gestational day (GD)-9-GD21] to BPA decreases the expression of members of the chemokine CXC family (Cxcl2, Cxcl4, Cxcl14, and Ccl20), interleukin-1 (Il1) gene family (Ill $\beta$ and Illrn), interleukin-2 gene family (Il7 receptor), and interferon gene family (interferon regulatory factor 9 (Ilr9), as well as immune response gene 1 ( $\operatorname{Irg} 1)$. These changes underscore a general impairment by BPA of antiinflammatory factors. Additionally, BPA lowers Esr1 (ER $\alpha)$ and augments Esr2 (ER $\beta)$, whose expression is linked to increased risk of breast cancer (65). In MMTV-erbB2 transgenic mice, a model of HER2-positive breast cancer, in utero BPA exposure (500 ng/kg) daily between GD11-GD19 induces in offspring mammary tumorigenesis, earlier puberty onset, accumulation of terminal end buds (TEB), and prolonged estrus phase. Increased proliferative mammary morphogenesis associates with accumulation of $\mathrm{ER} \alpha, p-\mathrm{ER} \alpha, \mathrm{CCND} 1$, and c-myc, concurrent with activation of erbB2, EGFR, erbB-3, Erk1/2, and Akt. In OVX female rat offspring, the gestational exposure of BPA (50 $\mu \mathrm{g}$ $\mathrm{BPA} / \mathrm{kg} /$ day from GD9 until weaning) elicits a higher incidence of ductal and atypical lobular hyperplasia in combination with E2 replacement compared to E2 alone. Thus, the perinatal exposure to BPA increases the susceptibility of mammary tissue to developing hyperplastic lesions (66).

The perinatal exposure to BPA increases the risk of proliferative lesions in offspring. In Wistar rats, in utero BPA exposure starting at GD7 through GD21 followed by lactational exposure through PND 22, induces mammary outgrowth in males at a low dose $(0.025 \mathrm{mg} \mathrm{BPA} / \mathrm{kg}$ body weight $/ \mathrm{d})$. Increased prevalence of intraductal hyperplasia is also observed in BPA females exposed in utero to BPA (0.25 mg/kg) (67). Similarly, in primates, mammary buds of female monkey offspring are denser and more developed as a result of in utero BPA exposure (68). In female C57/BL6 offspring, the perinatal exposure to BPA (3 $\mu \mathrm{g} / \mathrm{kg}-\mathrm{bw})$ increases the number of mammary epithelial cells and TEB; and expression of progesterone receptor (PR), Wnt family member-4 (Wnt-4), and receptor activator of nuclear factor $\kappa \mathrm{B}$ ligand (Rankl). These morphological and expression changes are induced by a level of exposure that approximates estimated daily BPA intake in formula-fed infants $(1-13 \mu \mathrm{g} / \mathrm{kg}-\mathrm{bw} / \mathrm{d})$ and associate with increased endpoints of breast cancer risk (69).

The exposure to bisphenols during early developmental stages imparts long-term effects. For example, a single neonatal exposure to BPA $(250 \mu \mathrm{g} / \mathrm{kg})$ decreases in female syngeneic $\mathrm{BALB} / \mathrm{c}$ mice the number of immunoglobin IgM that recognize tumor antigens (70). BPA-exposed mice develop larger tumors with a higher proportion of regulatory $\mathrm{T}$ lymphocytes expressing increased levels of $\mathrm{ER} \alpha$ (71). In Balb/c mice, exposure to BPA during puberty increases lateral branching and hyperplasia in adult mammary glands (72). Similarly, in female adult albino rats, BPA induces an increase in the number and size of acini and ducts in the mammary gland with hyperplasia of lining epithelial cells showing an increase in Ki-67 and caspase-3 (73). Taken together, these animal studies show that exposure to bisphenols during the perinatal, pubertal, and adult periods has the potential to alter mammary gland morphology and increase breast cancer risk.

\section{Human Environmental Exposures}

In human biological samples that were exposed at an environmental level, BPA is detected at concentrations ranging between 0.3 and $40 \mathrm{nM}$ from fetal serum and maternal plasma, respectively (74-76). Low doses of BPA exposure are defined as $\leq 5 \mathrm{mg} / \mathrm{kg}$ body weight $/ \mathrm{d}$ (69). In addition to direct exposure from food sources, BPA crosses the placenta and is found in breast milk. Free BPA is detected in $62 \%$ of milk samples $[\leq 0.22-10.8 \mathrm{ng} \mathrm{mL}(-1)$, median $0.68 \mathrm{ng} \mathrm{mL}(-1)$, mean $3.13 \mathrm{ng}$ $\mathrm{mL}(-1)]$ from a group $(n=21)$ of nursing mothers $(77)$. In a Chinese cohort, the blood BPA is higher in children (average 3.18 $\pm 1.66 \mathrm{ng} / \mathrm{ml})$ compared to adults $(0.2 \pm 0.10 \mathrm{ng} / \mathrm{ml})$ (78). Given their lipophilic property, bisphenols may accumulate in adipose tissue and exert long-term effects $(4,77)$. On the other hand, in breast adipose tissue samples provided by 36 breast cancer mastectomy patients and 14 reduction mammoplasty patients BPA concentrations are similar ( 0.39 vs. $0.41 \mathrm{ng} / \mathrm{g}, p=0.74)(79)$.

In studies of human urine, BPA is found in $96 \%$ [1,808 adults and 868 children (2013-2014 NHANES)] of samples randomly selected. Median level of BPA in US adults is $\sim 1.24 \mu \mathrm{g} / \mathrm{L}$ and higher than BPF $(0.35 \mu \mathrm{g} / \mathrm{L})$ and BPS $(0.37 \mu \mathrm{g} / \mathrm{L})$. For children, median BPA level are also higher $(1.25 \mu \mathrm{g} / \mathrm{L})$ than BPF and BPS 
(0.32 and $0.29 \mu \mathrm{g} / \mathrm{L}$, respectively). Bisphenol S is found in $81 \%$ of samples representing the US and seven Asian countries $(3,9)$. In the 2013-2014 NHANES database, BPA is found at higher concentrations among low socioeconomic status individuals and in children. Urinary BPA concentrations of young adults (18-25 years of age) are lower than those for adults aged $26+$ years, and associate with higher BMI (80).

Conjugation and deconjugation is a biochemical process that determines the levels of exposure to free and inactive bisphenols, respectively. Analysis of urine samples from a cohort of healthy full term ( $\geq 37$ weeks' gestation) neonates at two intervals of age (3-6 and 7-27 days) shows that only the inactive BPA glucuronide (BPAG), but not the free BPA form, is detected with concentrations ranging from $<0.1 \mu \mathrm{g} / \mathrm{L}$ to $11.21 \mu \mathrm{g} / \mathrm{L}$ (median: $0.27 \mu \mathrm{g} / \mathrm{L}$ ). These results confirm widespread BPA exposure in healthy full-term neonates, and efficient conjugation of BPA to its readily excretable and biologically inactive BPAG as early as 3 days of age (81). However, some studies suggest that cycling of conjugation/deconjugation maintains low but sustained basal levels of free BPA in the fetus (82). Fetal hepatic conjugation is low in early but increases in late pregnancy suggesting higher risk of exposure for the fetus in the early stages of fetal development (83).

Geographical location plays a major role in determining exposure to bisphenols. In a study with Bangladeshi, firstand second-generation Bangladeshi migrants to the UK, and white British girls, the average urinary BPAG increases and is significantly higher among white British $(0.007 \mathrm{ng} / \mathrm{mL})$ and second-generation British-Bangladeshi girls $(0.009 \mathrm{ng} / \mathrm{mL})$ compared to Bangladeshi girls $(0.002 \mathrm{ng} / \mathrm{mL})$. These findings point to birthplace and growth environment as variables affecting exposure to bisphenols (84). A study within the Early Life Exposure in Mexico to Environmental Toxicants (ELEMENT) birth cohort ( $n=120$ girls, age $8-13$ years), shows that BPA in the second trimester associates in offspring girls with higher peripubertal testosterone and higher odds of having a Tanner Stage $>1$ for breast development (OR/IQR: 2.2; 95\%CI: 1.0, 4.5). The association between in utero BPA exposure with earlier puberty may be due childhood obesity and adiposity, two conditions prevalent in young girls of Mexican ancestry (85). Similarly, in a population of Chilean girls, the higher tertile of BPA exposure associates with higher breast density (86), a factor known to increase the risk of breast cancer.

A Chinese study, albeit with a small sample size $(n=50)$ shows that BPA is detectable in a large percentage (84\%) of urine samples from adults (average $1.9 \pm 1.23 \mathrm{ng} / \mathrm{ml}$ ) ranging from 0.1 to $8.7 \mathrm{ng} / \mathrm{ml}$. Concentrations of BPA in urine (creatinineadjusted) in pregnant Chinese women receiving intravenous drip within $24 \mathrm{~h}$ of delivery approaches $\sim 7.0 \mathrm{ng} / \mathrm{ml}$ compared to only $0.4 \mathrm{ng} / \mathrm{ml}$ in women who do not receive intravenous treatment (78). While these results are from relatively small groups, they raise concerns about BPA exposure in particular in pregnant women for whom BPA concentrations $(\sim 30 \mathrm{nM})$ known to stimulate proliferation of breast cells have been detected in blood. Epidemiologic studies also confirm an association between urinary BPA levels and circulating inflammation-related markers in adult populations. In elderly subjects (60 years of age or older), higher urinary BPA are positively associated with inflammationrelated markers including white blood cell count, C-reactive protein (CRP), alanine (ALT) and aspartate AST) transaminase, and $\gamma$-glutamine transferase $(\gamma \mathrm{GTP})$ levels; and negatively associated with IL-10. The latter exerts anti-inflammatory and antitumor effects. These findings suggest that BPA exposure in adults induces inflammation and compromises cellular factors that protect against breast tumorigenesis (45).

\section{Epigenetics BPA}

Epigenetics refers to modifications in gene expression without changes in DNA and include changes in histone posttranslational modifications; DNA CpG methylation; and expression of noncoding RNA. Albeit limited, research data corroborate the epigenetic effects of exposure to bisphenols in breast tissue. BPA preferentially reduces $\mathrm{CpG}$ methylation at $\mathrm{ER} \alpha$ binding genes (87). Through this DNA modification bisphenols increase accessibility of transcription factors at E2-responsive genes which contribute to breast carcinogenesis (i.e., CCND1). In addition, bisphenols increase expression of factors involved in epigenetic silencing of tumor suppressor genes. One such factor is enhancer of zeste homolog 2 (EZH2), which is a methyltransferase specific to histone 3 lysine 27. EZH2 expression is induced by BPA through recruitment to the EZH2 promoter of ER, mixed lineage leukemia (MLL) and CBP/P300, which contribute to transcriptional activation (88). EZH2 expression and histone H3 trimethylation are elevated in ER $\alpha$-positive breast cancer cells and mammary tissue of mice exposed in utero to BPA (89). Increased expression of EZH2 associates with decreased nuclear expression of phospho-BRCA1 (Ser1423) and upregulation of phospho-Akt-1 (Ser473) in $\sim 40 \%$ of invasive breast carcinomas. Therefore, through upregulation of EZH2, exposure to bisphenols contributes to loss of genomic stability and increased proliferation mediated respectively by loss of BRCA1 and gain of PI3K/Akt-1 activity (90). Importantly, loss of BRCA1 enhances BPA-induced ER $\alpha$ signaling, cell proliferation, and mammary tumorigenesis (91). These results suggest that the breast cancer response to bisphenols is magnified in women who are BRCA1 mutation carries or in subjects with epigenetic silenced BRCA1 gene. Furthermore, DNA damage and disruption of cell cycle control by BPA associates with hypermethylation of various genes encoding factors that protect against breast cancer including TIMP metallopeptidase inhibitor 3 (TIMP3), which inhibits MMP involved in invasion and metastasis; checkpoint with forkhead and ring finger (CHFR), a tumor suppressor that delays passage into mitosis; ESR1 encoding for ER $\alpha$, whose expression is necessary to activate $B R C A 1$; and immunoglobulin superfamily member 4 (IGSF4), which participates in cell adhesion. Overall, loss of expression of these genes through hypermethylation is an epigenetic mechanism through which bisphenols increase susceptibility to breast tumorigenesis (92). The capacity for bisphenols to predispose to breast tumorigenesis finds support in the evidence that BPA induces proliferation and hypermethylation of BRCA1 in human non-tumor mammary epithelial cells (HMEC) (93). 
Homeobox A-D genes encode for transcription factors that exert differential effects on breast cancer. HOXC6 overexpression triggers expression of tumor growth factor and associates with breast cancer. It is induced epigenetically upon exposure to BPA both in vitro and in vivo. $\mathrm{ER} \alpha$ and ER-coregulators such as MLL are recruited to the HOXC6 promoter upon exposure to E2 or BPA and this triggers histone $\mathrm{H} 3 \mathrm{~K} 4$-trimethylation, histone acetylation, and recruitment of RNA polymerase II at the HOXC6 gene (94). Similarly, BPA induces expression of HOXB9, which contributes to cell proliferation. Mechanistically, ER $\alpha$ and the cofactors MLL-histone methylase (MLL3), CBP/P300, bind to the HOXB9 promoter at ERE in the presence of BPA leading to HOXB9 transactivation (95).

\section{BPA Analogs}

Bisphenol compounds exert differential DNA methylation alterations with the majority of these being ER-dependent $(\mathrm{BPA}>\mathrm{BPS}>\mathrm{BPF})$. In particular, BPA- and BPS-induced methylome alterations associated with focal adhesion, cGMPPKG, and cancer pathways (96). Higher proliferation in ER-positive breast cancer cells is noted following treatment with BPA or its substitute, BPS, accompanied by an ER $\alpha$-dependent decrease in genomic TET-catalyzed DNA hydroxymethylation. These findings highlight the E2-like activity of BPA/BPS and the epigenetic impact on breast tumorigenesis (97). The exposure of MCF-7 cells to BPS induces DNA methylation of transposons. Upon methylation, transposon become inactive with mutation of methylated cytosines $(\mathrm{C}>\mathrm{T})$ leading to loss of transposon function (38). Additionally, BPS upregulates genes (THBS4, PPARGC1A, CREB5, COL5A3) related to breast cancer progression. The $\mathrm{CpG}$ methylation status of breast cancer related genes (BRCA1, CDH1, PTEN, and CCND2) is also increased (38). These results suggest that BPS exposure plays a role in the progression of breast cancer through epigenetic changes hampering DNA repair and tumor suppressor functions.

\section{Bisphenols and Food Components}

Foods are important sources of exposure to bisphenols (Table 1) (6-9). A 24-h recall study of 1,101 girls (6-8 years of age) from the Breast Cancer and Environment Research Program (BCERP) shows increased urinary BPA levels associated with intake of grains, flour, fish, non-fresh vegetables, and poultry. Consumption of fats and oils are also positively associated with BPA exposure (98). Foods are also a vehicle of compounds that regulate the estrogenic effects of bisphenols. Unfortunately, this is an undeveloped area of research as only a few studies summarized below have examined the effects of food components in combination with bisphenols on endpoints of breast cancer.

\section{Cell Culture and Xenogratfs}

Genistein is the predominant isoflavone in soy. It regulates gene expression through ER $\alpha$ although with lower efficacy compared to E2 in ER $\alpha$-positive breast cells (99). In vitro, genistein synergizes with bisphenols to induce estrogenic responses. In HeLa-ER $\alpha$ and ER $\beta$ reporter cells, the coexposure to BPA and genistein, or SF, results in increased functional and transcriptional estrogenic effects, which are abolished by ER antagonists. Genistein- and BPA-induce gene expression profiles adversely linked to breast cancer prognosis similar to those induced by E2 both at low $(100 \mathrm{nM})$ and high doses $(10 \mu \mathrm{M})$ (29). Therefore, dietary intake of genistein may enhance the estrogenic effects of bisphenols. Chronic supplementation of MCF-7 cells with genistein and BPA $(50 \mathrm{nM})$ in vitro causes reduced expression of E2-responsive genes including MYC, EGR3, and HDAC11 associated with a decrease in H3K4me1. These changes are not reversed by removal of BPA and genistein suggesting these compounds epigenetically reprogram breast cells (100).

Resveratrol (trans-3,4,5-trihydroxystilbene; RES) is a naturally occurring phytoestrogen found in various foods including grapes and red wine. Studies related to the effects of RES in breast cells under conditions of exposure to BPA are limited. However, in E2-responsive MCF-7 CV cells, RES reverses cell proliferation induced by E2 or BPA by down-regulating the expressions of $\mathrm{ER} \alpha$, IGF-1R, p-IRS-1, and p-Akt1/2/3, and cyclin D1 at both transcriptional and translational levels (101). Whether or not RES is effective in breast tissue under conditions of exposure to bisphenols warrants further investigation.

Curcumin is a curcuminoid component of turmeric which has been extensively studied in cancer prevention and treatment. Curcumin inhibits the proliferative effects of BPA on MCF7 cells. The BPA-induced upregulation of oncogenic miR$19 \mathrm{a}$ and $\mathrm{miR}-19 \mathrm{~b}$, and the dysregulated expression of miR19-related downstream proteins, including PTEN, p-AKT, pMDM2, p53, and proliferating cell nuclear antigen are reversed by curcumin. These results suggest that curcumin modulates miR-19/PTEN/AKT/p53 axis to exhibit its protective effects against BPA-associated breast cancer promotion (102).

The compound 3,3'-diindolylmethane (DIM) originates from condensation of two indole-3-carbynol (I3C) moieties in the acidic environment of the stomach. Foods rich in I3C include broccoli, cabbage and cauliflower. The co-treatment with DIM $(20 \mu \mathrm{M})$ prevents E2- and BPA-induced cell proliferation, EMT, migration, and invasion of MCF-7 cells. Moreover, DIM decrease CXCR4 protein expression. These in vitro effects of DIM are also seen in a xenograft mouse model transplanted with MCF-7 breast cancer cells (103). Another compound found in cruciferous vegetables is the flavanol kaempferol. Whereas, BPA $(0.1-10 \mu \mathrm{M})$ and E2 $(0.01-0.0001 \mu \mathrm{M})$ induce cell proliferation of VM7Luc4E2 cells, these responses are antagonized by co-treatment with kaempferol $(30 \mu \mathrm{M})$ or DIM $(15 \mu \mathrm{M})$. BPA inhibits ROS production and apoptosis of VM7Luc4E2 cells similar to E2, but the co-treatment with kaempferol or DIM increases ROS production and apoptosis (104). These results suggest DIM and kaempferol may be an effective cruciferous components for the prevention of metastatic breast cancer resulting from exposure to bisphenols.

Naringenin is a flavanone found in grapefruit and oregano. It binds to $\mathrm{ER} \alpha$ and hampers cell proliferation by activating caspase-3. Also, the BPA-induced AKT activation is antagonized by naringenin, which prevents the antiapoptotic effects of BPA (105). Mechanistically, naringenin induces ER $\alpha$ protein accumulation by preventing proteasomal receptor degradation via activation of p38/MAPK pathway (106). 


\section{Animal Models}

Animal studies suggest that prepubertal exposure to genistein exerts preventative effects against endpoint associated with breast tumorigenesis. Results of a rodent study with lactating dams (Sprague-Dawley rats) shows that dietary genistein (250 ppm/diet) to achieve physiologically relevant serum concentrations $(\sim 700 \mathrm{pmol} / \mathrm{L})$ induces in offspring expression of factors involved in cancer prevention including MMP3; rhoassociated coiled-coil containing protein kinase 2 (ROCK2); neurosecretory protein VGF 8a (VGF), serine (or cysteine) proteinase inhibitor clade A (SERPINA1); ubiquitin carboxylterminal hydrolase L5 (UCH1); SET domain containing 2 (SETD2); and protein tyrosine phosphatase receptor type K (PTPRK) (107). The maternal nutrient supplementation with genistein $(250 \mathrm{ppm})$ counteracts BPA-induced DNA hypomethylation in early development (108). In prepubertal rats, the expression of annexin A2, VEGFR and Akt1 are increased in mammary tissue following treatment with BPA. Conversely, the dietary treatment with genistein exerts repressive effects on expression of these factors which contribute to various cancer processes such as angiogenesis, proliferation, and metastasis. These differential effects of BPA and genistein are proposed to contribute at least in part to their opposing effects on mammary carcinogenesis although both BPA and genistein elicit estrogenic effects (109). Two genes associated with improved survival, HPSE and RPS9, are hypomethylated in mammary tissue of rats exposed in prepuberty respectively to genistein alone or in combination with BPA (110).

A diet high in saturated fat (HFD) is negatively associated with breast cancer survival (111). During gestation, feeding a HFD along with a low exposure to BPA $(25 \mu \mathrm{g} / \mathrm{kg}$ BW/day) increases mammary tumor incidence in offspring, while reducing tumor-free survival time compared with the HFD alone. These in utero procarcinogenic effects of BPA associate with epigenetic reprogramming via $\mathrm{CpG}$ hypomethylation of Kcnv2 and hypermethylation of Car7 in mammary tissue of female offspring. These data suggest that concurrent exposure to a HFD and BPA during pregnancy increases mammary tumor incidence in offspring associated with epigenetic dysregulation (112).

\section{Clinical Studies}

Switching from a diet of canned foods or foods packaged in plastic to a diet of fresh foods reduces exposure to bisphenols. In a food intervention study, the urine levels of BPA metabolites decreased by $\sim 65 \%$ during the fresh foods intervention within 3 days. From this study, it seems that restricting intake of packaged and canned food is an effective approach to reducing exposure to bisphenols (113).

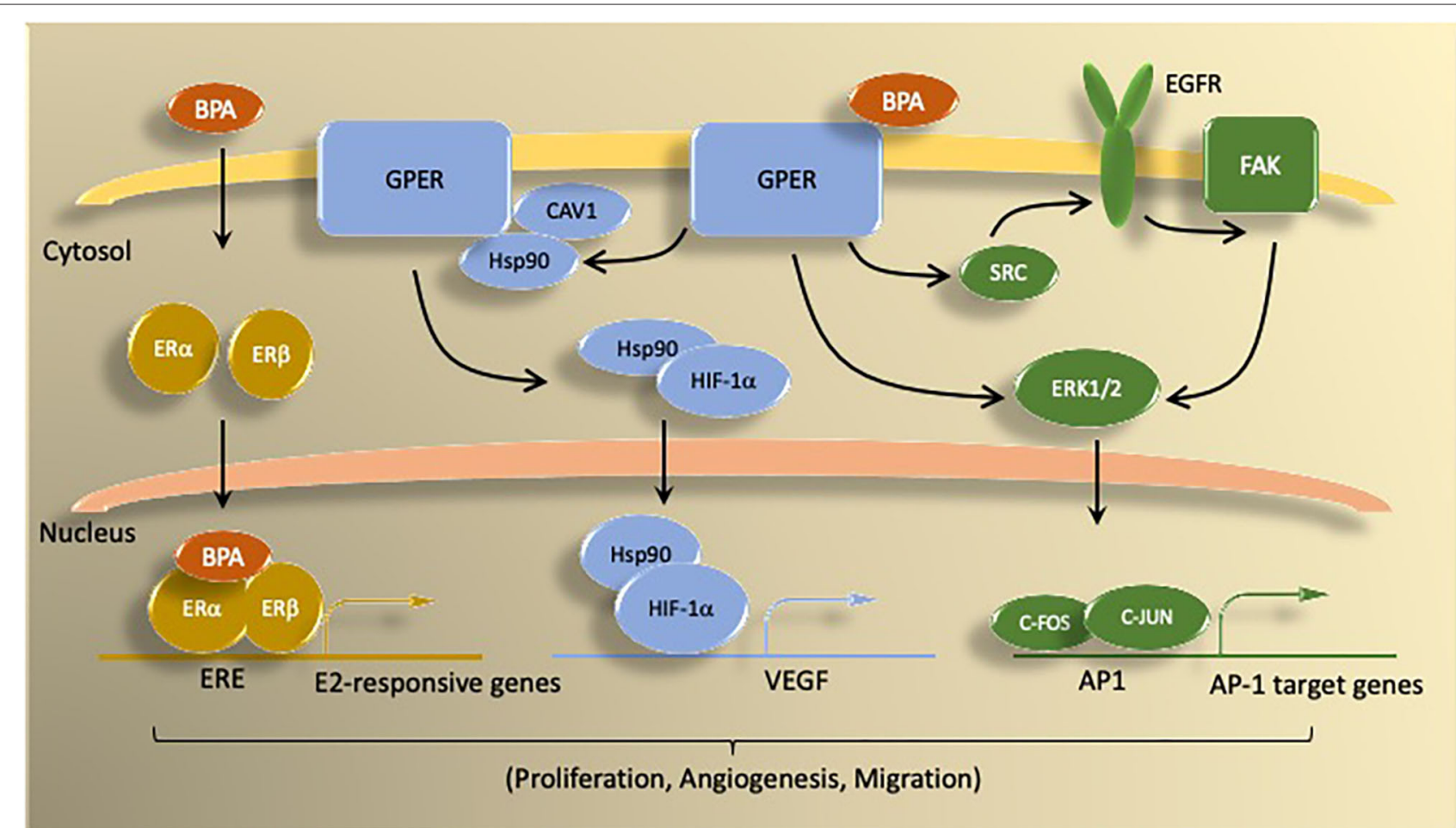

FIGURE 2 | Summary of BPA mechanisms of action via estrogen receptors. BPA activates both genomic and non-genomic estrogen signaling pathways. Genomic signaling involves activation of the nuclear ER proteins ER $\alpha$ and ER $\beta$. Nuclear ER bind as either homo- or heterodimers to induce transcription of genes controlled by estrogen responsive elements (ERE). Non-genomic actions of BPA involve signaling through G protein coupled estrogen receptor (GPER) molecules, which activate signal transduction pathways (e.g., ERK1/2) via kinase activity. BPA binding to GPER activates downstream signaling by epidermal growth factor receptor (EGFR) and focal adhesion kinase (FAK). GPER signaling through ERK1/2 stimulates transcription of c-FOS-dependent genes. Under hypoxic conditions, BPA activation of GPER promotes HIF1 $\alpha$-dependent induction of VEGF, which is associated with increased proliferation, migration, and angiogenesis. 
The Genes, Environment, and Health Initiative is a longitudinal study of girls enrolled at 6-7 years of age and followed through puberty. From the high-BPA group (average urinary $\mathrm{BPA}=17.5 \pm 11.2 \mathrm{ng} / \mathrm{g}$ - creatinine adjusted), several factors associated with cancer are increased and include ankyrin 2, a cytoskeletal protein involved in metastasis and migration; antigen Ki-67, which participates in cell proliferation; and E3 ubiquitin-ligase, talin 2, transient receptor potential channel 5 (TRPC5), mitogen-activated kinase kinase 4 (MKK4), and zinc finger 185 which are involved in cancer development. In blood of the high-genistein girls (average $1.3 \mu \mathrm{g} / \mathrm{g}$-creatinine adjusted), the nucleolar 7 and PR domain zinc finger 5 (PRDM5) factors with anticancer roles are upregulated. Differential gene regulation in girls with high concentrations of BPA and genistein are consistent with reported roles of BPA and genistein respectively in mammary cancer promotion and prevention. In blood of girls with high genistein concentrations in their urine, two proteins associated with cancer were down regulated: endothelin-converting enzyme (ECE-1) and eukaryotic translation initiation factor 3 subunit J (EIF-3). Conversely, nucleolar 7 and PR domain zinc finger 5 (PRDM5) are proteins that are upregulated in high-genistein girls. The nucleolar 7 gene is a tumor suppressor gene antagonizing the angiogenic process. PRDM5 has growth suppressive activities and is silenced in breast, ovarian, liver, lung, colon, and other cancers. All four proteins should be considered as biomarkers of susceptibility for genistein/soy and cancer prevention (114).

\section{DISCUSSION AND CONCLUSIONS}

Bisphenols exhibit vast actions on endocrine regulation (Figure 2) and appear to contribute to the progression of ER positive and ER-negative breast tumors. However, several questions have not been conclusively addressed in previous studies. Given the potential estrogenic effects of BPA in neonates, chemical analogs such as BPF, BPAF, and BPS have been introduced in industrial processes. However, in available, albeit limited, studies these analogs demonstrate similar or even stronger estrogenic, and possibly carcinogenic, effects as the parent BPA compound. Therefore, research that addresses the effects of dose and timing of exposure to bisphenol analogs is warranted. This is particularly important as exposure to bisphenols appears to impact epigenetic gene expression by upregulating genes involved in cancer processes while silencing genes with tumor suppressor functions (i.e., BRCA1). Of particular concern is the fact that removal of bisphenols may not be sufficient to reverse the epigenetic marks on genes. Therefore,

\section{REFERENCES}

1. Bisphenol A, CID=6623. National Center for Biotechnology Information. Available online at: https://pubchem.ncbi.nlm.nih.gov/compound/ Bisphenol-A (accessed March 07, 2020).

2. Shafei A, Ramzy MM, Hegazy AI, Husseny AK, El-Hadary UG, Taha MM, et al. The molecular mechanisms of action of the the potential exists for exposure to bisphenols at different stage of life (i.e., gestation, prepuberty, adult) to permanently silence genes with tumor suppressor functions, while eliciting the constitutive activation of oncogenes.

Another important area for investigation pertains to the effects of bisphenols on breast cancer subtypes. While most emphasis is placed on the estrogenic effects of bisphenols through activation of ER, it appears bisphenols can also promote growth of ER-negative and TNBC cells through non-ER mediated mechanisms. Under the assumption that the timing and dose of bisphenol exposure in animal models mimics that of humans, one of the most vulnerable populations is infants, who regardless of their nutrition source (placenta in utero, then breastmilk or formula) may be exposed to bisphenols while simultaneously undergoing the most significant period of development. Further, the results summarized here indicate that individuals carriers of mutations or epigenetic marks (i.e., CpG methylation) in breast cancer genes (i.e., BRCA1) may be at higher risk from exposure to bisphenols.

Finally, more emphasis should be placed on research about foods (and their packaging) as vehicles of exposure to bisphenols and bioactive components that prevent the biochemical changes induced in breast tissue by bisphenols. To date, research about the effects of diet and bioactive food components on bisphenolrelated breast tumorigenesis is scarce making it difficult to make any clinically relevant conclusions about surveillance and dietary interventions. However, a few studies have highlighted the possible preventative effects of compounds found in cruciferous vegetables, grapefruit, grapes, and turmeric. While some cell culture studies have raised concerns about the additive effects of soy genistein with bisphenols, most animal studies suggest it exerts a preventative effect when exposure occurs during the prepubertal phase of life. Ultimately, as clinicians wait for further research, and bisphenols remain ubiquitous in the environment, it is advisable to limit exposure to BPA by avoiding heating food in plastic containers and avoiding the use of canned food and foods packaged with polycarbonate plastics for breast cancer risk reduction.

\section{AUTHOR CONTRIBUTIONS}

$\mathrm{BS}, \mathrm{AB}, \mathrm{DR}, \mathrm{LN}, \mathrm{MD}$, and $\mathrm{OS}$ contributed to the conception and development of the manuscript. BS, AB, and DR had primary responsibility for the writing of the manuscript. LN was responsible for the clinical content of the work and contributed to the writing and review of the manuscript. All authors contributed to the article and approved the submitted version. 
4. Wazir U, Mokbel K. Bisphenol A: a concise review of literature and a discussion of health and regulatory implications. In vivo. (2019) 33:1421-3. doi: 10.21873/invivo.11619

5. Waks AG, Winer EP. Breast cancer treatment: a review. JAMA. (2019) 321:288-300. doi: 10.1001/jama.2018.19323

6. Noonan GO, Ackerman LK, Begley TH. Concentration of bisphenol A in highly consumed canned foods on the US market. J Agric Food Chem. (2011) 59:7178-85. doi: 10.1021/jf201076f

7. Cao XL, Kosarac I, Popovic S, Zhou S, Smith D, Dabeka R. LC-MS/MS analysis of bisphenol $S$ and five other bisphenols in total diet food samples. Food Addit Contam A Chem Anal Control Expo Risk Assess. (2019) 36:1740-7. doi: 10.1080/19440049.2019.1643042

8. Schecter A, Malik N, Haffner D, Smith S, Harris TR, Paepke O, et al. Bisphenol A (BPA) in US food. Environ Sci Technol. (2010) 44:942530. doi: 10.1021/es102785d

9. Álvarez-Muñoz D, Rodríguez-Mozaz S, Jacobs S, Serra-Compte A, Cáceres $\mathrm{N}$, Sioen I, et al. Pharmaceuticals and endocrine disruptors in raw and cooked seafood from European market: concentrations and human exposure levels. Environ Int. (2018) 119:570-81. doi: 10.1016/j.envint.2018. 07.006

10. Allard P. Bisphenol A. In: Gupta R, editor. Biomarkers in Toxicology. New York, NY: Academic Press (2014). p. 459-74. doi: 10.1016/B978-0-12-404630-6.00027-0

11. Liao C, Kannan K. Concentrations and profiles of bisphenol A and other bisphenol analogues in foodstuffs from the United States and their implications for human exposure. J Agric Food Chem. (2013) 61:4655-62. doi: 10.1021/jf400445n

12. EFSA. Food is Main Source of BPA for Consumers, Thermal Paper also Potentially Significant: European Food Safety Authority. (2013). Available online at: http://www.efsa.europa.eu/en/press/news/130725 (accessed March 05, 2020).

13. Cao XL, Perez-Locas C, Dufresne G, Clement G, Popovic S, Beraldin F, et al. Concentrations of bisphenol $\mathrm{A}$ in the composite food samples from the 2008 Canadian total diet study in Quebec City and dietary intake estimates. Food Addit Contam A Chem Anal Control Expo Risk Assess. (2011) 28:791-8. doi: 10.1080/19440049.2010.513015

14. Lehmler HJ, Liu B, Gadogbe M, Bao W. Exposure to Bisphenol A, Bisphenol F, and Bisphenol S in US adults and children: the National health and nutrition examination survey 2013-2014. ACS Omega. (2018) 3:6523-32. doi: 10.1021/acsomega.8b00824

15. Sakhi AK, Lillegaard IT, Voorspoels S, Carlsen MH, Løken EB, Brantsæter AL, et al. Concentrations of phthalates and bisphenol A in Norwegian foods and beverages and estimated dietary exposure in adults. Environ Int. (2014) 73:259-69. doi: 10.1016/j.envint.2014. 08.005

16. FDA. Bisphenol A (BPA): Use in Food Contact Application: USFDA. (2010). Available online at: https://www.fda.gov/food/food-additives-petitions/ bisphenol-bpa-use-food-contact-application (accessed November, 2014).

17. EPA. Integrated Risk Information System: US Environmental Protection Agency. (2012). Available online at: https://www.epa.gov/iris (accessed April 23, 2020).

18. Diamanti-Kandarakis E, Bourguignon JP, Giudice LC, Hauser R, Prins GS, Soto AM, et al. Endocrine-disrupting chemicals: an Endocrine society scientific statement. Endocr Rev. (2009) 30:293-342. doi: 10.1210/er.2009-0002

19. EPA. Risk Management for Bisphenol A (BPA): US Environmental Protection Agency. (2017). Available online at: https://www.epa.gov/assessingand-managing-chemicals-under-tsca/risk-management-bisphenol-bpa (accessed April 17, 2020).

20. eur-lex.europa. Commission Regulation (EU) 2016/2235 of 12 December 2016 Amending Annex XVII to Regulation (EC) No 1907/2006 of the European Parliament and of the Council concerning the Registration, Evaluation, Authorisation and Restriction of Chemicals (REACH) as regards bisphenol A: Official Journal of the European Union. (2016). Available online at: https:// eur-lex.europa.eu/eli/reg/2016/2235/oj (accessed March 05, 2020).

21. Abboud A. Edward Charles Dodds: The Embryo Project Encyclopedia. (2017). Available online at: https://embryo.asu.edu/handle/10776/11438 (accessed April 23, 2020).
22. Delfosse V, Grimaldi M, Pons JL, Boulahtouf A, le Maire A, Cavailles V, et al. Structural and mechanistic insights into bisphenols action provide guidelines for risk assessment and discovery of bisphenol A substitutes. Proc Natl Acad Sci USA. (2012) 109:14930-5. doi: 10.1073/pnas.1203574109

23. Acconcia F, Pallottini V, Marino M. Molecular mechanisms of action of BPA. Dose Response. (2015) 13:1559325815610582. doi: 10.1177/1559325815610582

24. Park C, Lee J, Kong B, Park J, Song H, Choi K, et al. The effects of bisphenol A, benzyl butyl phthalate, and di(2-ethylhexyl) phthalate on estrogen receptor alpha in estrogen receptor-positive cells under hypoxia. Environ Pollut. (2019) 248:774-81. doi: 10.1016/j.envpol.2019.02.069

25. Lee HS, Park EJ, Oh JH, Moon G, Hwang MS, Kim SY, et al. Bisphenol A exerts estrogenic effects by modulating CDK1/2 and p38 MAP kinase activity. Biosci Biotechnol Biochem. (2014) 78:13715. doi: 10.1080/09168451.2014.921557

26. Al-Bader M, Ford C, Al-Ayadhy B, Francis I. Analysis of estrogen receptor isoforms and variants in breast cancer cell lines. Exp Ther Med. (2011) 2:537-44. doi: 10.3892/etm.2011.226

27. Sellitto A, D'Agostino Y, Alexandrova E, Lamberti J, Pecoraro G, Memoli D, et al. Insights into the role of estrogen receptor $\beta$ in triple-negative breast cancer. Cancers. (2020) 12:1477. doi: 10.3390/cancers 12061477

28. Hirao-Suzuki M, Takeda S, Okuda K, Takiguchi M, Yoshihara S. Repeated exposure to 4-Methyl-2,4-bis(4-hydroxyphenyl)pent-1-ene (MBP), an active metabolite of Bisphenol A, aggressively stimulates breast cancer cell growth in an estrogen receptor $\beta$ (ER $\beta$ )-dependent manner. Mol Pharmacol. (2019) 95:260-8. doi: 10.1124/mol.118.114124

29. Katchy A, Pinto C, Jonsson P, Nguyen-Vu T, Pandelova M, Riu A, et al. Coexposure to phytoestrogens and bisphenol a mimics estrogenic effects in an additive manner. Toxicol Sci. (2014) 138:21-35. doi: 10.1093/toxsci/kft271

30. Dong S, Terasaka S, Kiyama R. Bisphenol A induces a rapid activation of Erk1/2 through GPR30 in human breast cancer cells. Environ Pollut. (2011) 159:212-8. doi: 10.1016/j.envpol.2010.09.004

31. Castillo-Sanchez R, Ramirez-Ricardo J, Martinez-Baeza E, Cortes-Reynosa P, Candanedo-Gonzales F, Gomez R, et al. Bisphenol A induces focal adhesions assembly and activation of FAK, Src and ERK2 via GPER in MDA-MB-231 breast cancer cells. Toxicol in vitro. (2020) 66:104871. doi: 10.1016/j.tiv.2020.104871

32. Pupo M, Pisano A, Lappano R, Santolla MF, de Francesco EM, Abonante $\mathrm{S}$, et al. Bisphenol A induces gene expression changes and proliferative effects through GPER in breast cancer cells and cancer-associated fibroblasts. Environ Health Perspect. (2012) 120:1177-82. doi: 10.1289/ehp.1104526

33. Xu F, Wang X, Wu N, He S, Yi W, Xiang S, et al. Bisphenol A induces proliferative effects on both breast cancer cells and vascular endothelial cells through a shared GPER-dependent pathway in hypoxia. Environ Pollut. (2017) 231:1609-20. doi: 10.1016/j.envpol.2017.09.069

34. Merzoug-Larabi M, Youssef I, Bui AT, Legay C, Loiodice S, Lognon $\mathrm{S}$, et al. Protein kinase D1 (PKD1) is a new functional non-genomic target of Bisphenol A in breast cancer cells. Front Pharmacol. (2019) 10:1683. doi: 10.3389/fphar.2019.01683

35. Lloyd V, Morse M, Purakal B, Parker J, Benard P, Crone M, et al. Hormone-like effects of Bisphenol $A$ on p53 and estrogen receptor alpha in breast cancer cells. Biores Open Access. (2019) 8:169-84. doi: 10.1089/biores.2018.0048

36. Vydra N, Janus P, Toma-Jonik A, Stokowy T, Mrowiec K, Korfanty J, et al. 17 $\beta$-estradiol activates HSF1 via MAPK signaling in ER $\alpha$-positive breast cancer cells. Cancers. (2019). 11:101533. doi: 10.3390/cancers11101533

37. Williams GP, Darbre PD. Low-dose environmental endocrine disruptors, increase aromatase activity, estradiol biosynthesis and cell proliferation in human breast cells. Mol Cell Endocrinol. (2019) 486:55-64. doi: 10.1016/j.mce.2019.02.016

38. Huang W, Zhao C, Zhong H, Zhang S, Xia Y, Cai Z. Bisphenol S induced epigenetic and transcriptional changes in human breast cancer cell line MCF7. Environ Pollut. (2019) 246:697-703. doi: 10.1016/j.envpol.2018.12.084

39. Lillo MA, Nichols C, Seagroves TN, Miranda-Carboni GA, Krum SA. Bisphenol A induces Sox 2 in $\mathrm{ER}(+)$ breast cancer stem-like cells. Horm Cancer. (2017) 8:90-9. doi: 10.1007/s12672-017-0286-5

40. Yuan S, Huang C, Ji X, Ma M, Rao K, Wang Z. Prediction of the combined effects of multiple estrogenic chemicals on MCF-7 human breast 
cancer cells and a preliminary molecular exploration of the estrogenic proliferative effects and related gene expression. Ecotoxicol Environ Saf. (2018) 160:1-9. doi: 10.1016/j.ecoenv.2018.05.025

41. Wang X, Luo N, Xu Z, Zheng X, Huang B, Pan X. The estrogenic proliferative effects of two alkylphenols and a preliminary mechanism exploration in MCF-7 breast cancer cells. Environ Toxicol. (2020) 35:628-38. doi: 10.1002/tox.22898

42. Kim H, Kim HS, Moon WK. Comparison of transcriptome expression alterations by chronic exposure to low-dose bisphenol A in different subtypes of breast cancer cells. Toxicol Appl Pharmacol. (2019) 385:114814. doi: 10.1016/j.taap.2019.114814

43. Hsing $\mathrm{CH}$, Cheng $\mathrm{HC}$, Hsu $\mathrm{YH}$, Chan $\mathrm{CH}$, Yeh $\mathrm{CH}$, Li CF, et al. Upregulated IL-19 in breast cancer promotes tumor progression and affects clinical outcome. Clin Cancer Res. (2012) 18:713-25. doi: 10.1158/1078-0432.CCR-11-1532

44. Zhu A, Yuan P, Du F, Hong R, Ding X, Shi X, et al. SPARC overexpression in primary tumors correlates with disease recurrence and overall survival in patients with triple negative breast cancer. Oncotarget. (2016) 7:76628-34. doi: 10.18632/oncotarget.10532

45. Song H, Park J, Bui PTC, Choi K, Gye MC, Hong YC, et al. Bisphenol A induces COX-2 through the mitogen-activated protein kinase pathway and is associated with levels of inflammationrelated markers in elderly populations. Environ Res. (2017) 158:490-8. doi: 10.1016/j.envres.2017.07.005

46. Sauer SJ, Tarpley M, Shah I, Save AV, Lyerly HK, Patierno SR, et al. Bisphenol A activates EGFR and ERK promoting proliferation, tumor spheroid formation and resistance to EGFR pathway inhibition in estrogen receptor-negative inflammatory breast cancer cells. Carcinogenesis. (2017) 38:252-60. doi: 10.1093/carcin/bgx003

47. Zhang XL, Liu N, Weng SF, Wang HS. Bisphenol A increases the migration and invasion of triple-negative breast cancer cells via oestrogen-related receptor gamma. Basic Clin Pharmacol Toxicol. (2016) 119:389-95. doi: 10.1111/bcpt.12591

48. Castillo Sanchez R, Gomez R, Perez Salazar E. Bisphenol A induces migration through a GPER-, FAK-, Src-, and ERK2-dependent pathway in MDA-MB-231 breast cancer cells. Chem Res Toxicol. (2016) 29:285-95. doi: 10.1021/acs.chemrestox.5b00457

49. Zhang XL, Wang HS, Liu N, Ge LC. Bisphenol A stimulates the epithelial mesenchymal transition of estrogen negative breast cancer cells via FOXA1 signals. Arch Biochem Biophys. (2015) 585:10-6. doi: 10.1016/j.abb.2015.09.006

50. Liao C, Liu F, Kannan K. Bisphenol s, a new bisphenol analogue, in paper products and currency bills and its association with bisphenol a residues. Environ Sci Technol. (2012) 46:6515-22. doi: 10.1021/es300876n

51. Mesnage R, Phedonos A, Biserni M, Arno M, Balu S, Corton JC, et al. Evaluation of estrogen receptor alpha activation by glyphosate-based herbicide constituents. Food Chem Toxicol. (2017) 108:30-42. doi: 10.1016/j.fct.2017.07.025

52. Kim JY, Choi HG, Lee HM, Lee GA, Hwang KA, Choi KC. Effects of bisphenol compounds on the growth and epithelial mesenchymal transition of MCF-7 CV human breast cancer cells. J Biomed Res. (2017) 31:358-69. doi: 10.7555/JBR.31.20160162

53. Awada Z, Nasr R, Akika R, Ghantous A, Hou L, Zgheib NK. Effect of bisphenols on telomerase expression and activity in breast cancer cell lines. Mol Biol Rep. (2020) 47:3541-9. doi: 10.1007/s11033-02005444-0

54. Zhao Q, Howard EW, Parris AB, Ma Z, Xing Y, Yang X. Bisphenol AF promotes estrogen receptor-positive breast cancer cell proliferation through amphiregulin-mediated crosstalk with receptor tyrosine kinase signaling. PLoS ONE. (2019) 14:e0216469. doi: 10.1371/journal.pone.0216469

55. Lei B, Sun S, Zhang X, Feng C, Xu J, Wen Y, et al. Bisphenol AF exerts estrogenic activity in MCF-7 cells through activation of Erk and PI3K/Akt signals via GPER signaling pathway. Chemosphere. (2019) 220:362-70. doi: 10.1016/j.chemosphere.2018.12.122

56. Lei B, Sun S, Xu J, Feng C, Yu Y, Xu G, et al. Low-concentration BPAF- and BPF-induced cell biological effects are mediated by ROS in MCF-7 breast cancer cells. Environ Sci Pollut Res Int. (2018) 25:3200-8. doi: 10.1007/s11356-017-9709-7
57. Li M, Han X, Gao W, Chen F, Shao B. Bisphenol AF stimulates transcription and secretion of C-X-C chemokine ligand 12 to promote proliferation of cultured T47D breast cancer cells. Toxicology. (2015) 338:30-6. doi: 10.1016/j.tox.2015.09.007

58. Okazaki H, Hirao-Suzuki M, Takeda S, Takemoto Y, Mizunoe R, Haraguchi $\mathrm{K}$, et al. Bisphenol AF as an activator of human estrogen receptor $\beta 1$ (ER $\beta 1$ ) in breast cancer cell lines. J Toxicol Sci. (2018) 43:3217. doi: $10.2131 /$ jts. 43.321

59. Lin Z, Zhang X, Zhao F, Ru S. Bisphenol S promotes the cell cycle progression and cell proliferation through ER $\alpha$-cyclin D-CDK4/6-pRb pathway in MCF-7 breast cancer cells. Toxicol Appl Pharmacol. (2019) 366:75-82. doi: 10.1016/j.taap.2019.01.017

60. Huang W, Zhu L, Zhao C, Chen X, Cai Z. Integration of proteomics and metabolomics reveals promotion of proliferation by exposure of bisphenol S in human breast epithelial MCF-10A cells. Sci Total Environt. (2020) 712:136453. doi: 10.1016/j.scitotenv.2019.136453

61. Atlas E, Dimitrova V. Bisphenol S and Bisphenol A disrupt morphogenesis of MCF-12A human mammary epithelial cells. Sci Rep. (2019) 9:16005. doi: 10.1038/s41598-019-52505-x

62. Deng Q, Jiang G, Wu Y, Li J, Liang W, Chen L, et al. GPER/HippoYAP signal is involved in Bisphenol $S$ induced migration of triple negative breast cancer (TNBC) cells. J Hazard Mater. (2018) 355:1-9. doi: 10.1016/j.jhazmat.2018.05.013

63. Kim H, Kim HS, Piao YJ, Moon WK. Bisphenol A promotes the invasive and metastatic potential of ductal carcinoma in situ and protumorigenic polarization of macrophages. Toxicol Sci. (2019) 170:283-95. doi: 10.1093/toxsci/kfz119

64. Weber Lozada K, Keri RA. Bisphenol A increases mammary cancer risk in two distinct mouse models of breast cancer. Biol Reprod. (2011) 85:490-7. doi: 10.1095/biolreprod.110.090431

65. Fischer C, Mamillapalli R, Goetz LG, Jorgenson E, Ilagan Y, Taylor HS. Bisphenol A (BPA) exposure in utero leads to immunoregulatory cytokine dysregulation in the mouse mammary gland: a potential mechanism programming breast cancer risk. Horm Cancer. (2016) 7:241-51. doi: 10.1007/s12672-016-0254-5

66. Gomez AL, Delconte MB, Altamirano GA, Vigezzi L, Bosquiazzo VL, Barbisan LF, et al. Perinatal exposure to Bisphenol A or diethylstilbestrol increases the susceptibility to develop mammary gland lesions after estrogen replacement therapy in middle-aged rats. Horm Cancer. (2017) 8:78-89. doi: 10.1007/s12672-016-0282-1

67. Mandrup K, Boberg J, Isling LK, Christiansen S, Hass U. Low-dose effects of bisphenol A on mammary gland development in rats. Andrology. (2016) 4:673-83. doi: 10.1111/andr.12193

68. Tharp AP, Maffini MV, Hunt PA, VandeVoort CA, Sonnenschein C, Soto AM. Bisphenol A alters the development of the rhesus monkey mammary gland. Proc Natl Acad Sci USA. (2012) 109:8190-5. doi: 10.1073/pnas.1120488109

69. Ayyanan A, Laribi O, Schuepbach-Mallepell S, Schrick C, Gutierrez M, Tanos T, et al. Perinatal exposure to bisphenol a increases adult mammary gland progesterone response and cell number. Mol Endocrinol. (2011) 25:1915-23. doi: 10.1210/me.2011-1129

70. Hernández Avila R, Palacios-Arreola MI, Nava-Castro KE, Morales-Montor J, Ostoa-Saloma P. Neonatal Bisphenol A exposure affects the IgM humoral immune response to $4 \mathrm{~T} 1$ breast carcinoma cells in mice. Int J Environ Res Public Health. (2019) 16:1784. doi: 10.3390/ijerph16101784

71. Palacios-Arreola MI, Nava-Castro KE, Río-Araiza VHD, Pérez-Sánchez NY, Morales-Montor J. A single neonatal administration of Bisphenol A induces higher tumour weight associated to changes in tumour microenvironment in the adulthood. Sci Rep. (2017) 7:10573. doi: 10.1038/s41598-017-10135-1

72. Wang D, Gao H, Bandyopadhyay A, Wu A, Yeh IT, Chen Y, et al. Pubertal bisphenol A exposure alters murine mammary stem cell function leading to early neoplasia in regenerated glands. Cancer Prevent Res. (2014) 7:445-55. doi: 10.1158/1940-6207.CAPR-13-0260

73. Ibrahim MA, Elbakry RH, Bayomy NA. Effect of bisphenol A on morphology, apoptosis and proliferation in the resting mammary gland of the adult albino rat. Int J Exp Pathol. (2016) 97:27-36. doi: 10.1111/iep.12164

74. Schönfelder G, Wittfoht W, Hopp H, Talsness CE, Paul M, Chahoud I. Parent bisphenol A accumulation in the human maternal-fetal-placental 
unit. Environ Health Perspect. (2002) 110:A703-7. doi: 10.1289/ehp.0211 00703

75. Welshons WV, Nagel SC, vom Saal FS. Large effects from small exposures. III. Endocrine mechanisms mediating effects of bisphenol A at levels of human exposure. Endocrinology. (2006) 147(6 Suppl.):S5669. doi: 10.1210/en.2005-1159

76. Vandenberg LN, Chahoud I, Heindel JJ, Padmanabhan V, Paumgartten FJ, Schoenfelder G. Urinary, circulating, and tissue biomonitoring studies indicate widespread exposure to bisphenol A. Environ Health Perspect. (2010) 118:1055-70. doi: 10.1289/ehp.0901716

77. Zimmers SM, Browne EP, O'Keefe PW, Anderton DL, Kramer L, Reckhow $\mathrm{DA}$, et al. Determination of free Bisphenol A (BPA) concentrations in breast milk of US women using a sensitive LC/MS/MS method. Chemosphere. (2014) 104:237-43. doi: 10.1016/j.chemosphere.2013.12.085

78. Zhang T, Sun H, Kannan K. Blood and urinary bisphenol A concentrations in children, adults, and pregnant women from china: partitioning between blood and urine and maternal and fetal cord blood. Environ Sci Technol. (2013) 47:4686-94. doi: 10.1021/es303808b

79. Reeves KW, Schneider S, Xue J, Kannan K, Mason H, Johnson M, et al. Bisphenol-A in breast adipose tissue of breast cancer cases and controls. Environ Res. (2018) 167:735-8. doi: 10.1016/j.envres.2018.08.033

80. van Woerden I, Bruening M, Montresor-López J, Payne-Sturges DC. Trends and disparities in urinary BPA concentrations among US emerging adults. Environ Res. (2019) 176:108515. doi: 10.1016/j.envres.2019.05.046

81. Nachman RM, Fox SD, Golden WC, Sibinga E, Groopman JD, Lees PS. Serial free bisphenol A and Bisphenol A glucuronide concentrations in neonates. J Pediatr. (2015) 167:64-9. doi: 10.1016/j.jpeds.2015.03.036

82. Gauderat G, Picard-Hagen N, Toutain PL, Corbel T, Viguié C, Puel $\mathrm{S}$, et al. Bisphenol A glucuronide deconjugation is a determining factor of fetal exposure to bisphenol A. Environ Int. (2016) 86:52-9. doi: 10.1016/j.envint.2015.10.006

83. Corbel T, Perdu E, Gayrard V, Puel S, Lacroix MZ, Viguié $\mathrm{C}$, et al. Conjugation and deconjugation reactions within the fetoplacental compartment in a sheep model: a key factor determining bisphenol A fetal exposure. Drug Metab Dispos. (2015) 43:467-76. doi: 10.1124/dmd.114.061291

84. Howland RE, Deziel NC, Bentley GR, Booth M, Choudhury OA, Hofmann $\mathrm{JN}$, et al. Assessing endogenous and exogenous hormone exposures and breast development in a migrant study of bangladeshi and british girls. Int J Environ Res Public Health. (2020) 17:1185. doi: 10.3390/ijerph17041185

85. Watkins DJ, Sánchez BN, Téllez-Rojo MM, Lee JM, Mercado-García A, Blank-Goldenberg C, et al. Phthalate and bisphenol A exposure during in utero windows of susceptibility in relation to reproductive hormones and pubertal development in girls. Environ Res. (2017) 159:143-51. doi: 10.1016/j.envres.2017.07.051

86. Binder AM, Corvalan C, Pereira A, Calafat AM, Ye X, Shepherd J, et al. Prepubertal and pubertal endocrine-disrupting chemical exposure and breast density among Chilean adolescents. Cancer Epidemiol Biomarkers Prevent. (2018) 27:1491-9. doi: 10.1158/1055-9965.EPI-17-0813

87. Jorgensen EM, Alderman MH 3rd, Taylor HS. Preferential epigenetic programming of estrogen response after in utero xenoestrogen (bisphenol-A) exposure. FASEB J. (2016) 30:3194-201. doi: 10.1096/fj.201500089R

88. Bhan A, Hussain I, Ansari KI, Bobzean SA, Perrotti LI, Mandal SS. Histone methyltransferase EZH2 is transcriptionally induced by estradiol as well as estrogenic endocrine disruptors bisphenol-A and diethylstilbestrol. J Mol Biol. (2014) 426:3426-41. doi: 10.1016/j.jmb.2014.07.025

89. Doherty LF, Bromer JG, Zhou Y, Aldad TS, Taylor HS. In utero exposure to diethylstilbestrol (DES) or bisphenol-A (BPA) increases EZH2 expression in the mammary gland: an epigenetic mechanism linking endocrine disruptors to breast cancer. Horm Cancer. (2010) 1:146-55. doi: 10.1007/s12672-010-0015-9

90. Gonzalez ME, DuPrie ML, Krueger H, Merajver SD, Ventura AC, Toy $\mathrm{KA}$, et al. Histone methyltransferase EZH2 induces Akt-dependent genomic instability and BRCA1 inhibition in breast cancer. Cancer Res. (2011) 71:2360-70. doi: 10.1158/0008-5472.CAN-10-1933

91. Jones LP, Sampson A, Kang HJ, Kim HJ, Yi YW, Kwon SY, et al. Loss of BRCA1 leads to an increased sensitivity to Bisphenol A. Toxicol Lett. (2010) 199:261-8. doi: 10.1016/j.toxlet.2010.09.008
92. Nair VA, Valo S, Peltomäki P, Bajbouj K, Abdel-Rahman WM. Oncogenic potential of Bisphenol A and common environmental contaminants in human mammary epithelial cells. Int J Mol Sci. (2020) 21:3735. doi: $10.3390 /$ ijms 21103735

93. Qin XY, Fukuda T, Yang L, Zaha H, Akanuma H, Zeng Q, et al. Effects of bisphenol A exposure on the proliferation and senescence of normal human mammary epithelial cells. Cancer Biol Ther. (2012) 13:296-306. doi: 10.4161/cbt.18942

94. Hussain I, Bhan A, Ansari KI, Deb P, Bobzean SA, Perrotti LI, et al. Bisphenol-A induces expression of HOXC6, an estrogen-regulated homeobox-containing gene associated with breast cancer. Biochim Biophys Acta. (2015) 1849:697-708. doi: 10.1016/j.bbagrm.2015.02.003

95. Deb P, Bhan A, Hussain I, Ansari KI, Bobzean SA, Pandita TK, et al. Endocrine disrupting chemical, bisphenol-A, induces breast cancer associated gene HOXB9 expression in vitro and in vivo. Gene. (2016) 590:234-43. doi: 10.1016/j.gene.2016.05.009

96. Awada Z, Nasr R, Akika R, Cahais V, Cuenin C, Zhivagui M, et al. DNA methylome-wide alterations associated with estrogen receptordependent effects of bisphenols in breast cancer. Clin Epigenetics. (2019) 11:138. doi: 10.1186/s13148-019-0725-y

97. Li Z, Lyu C, Ren Y, Wang H. Role of TET dioxygenases and DNA hydroxymethylation in bisphenols-stimulated proliferation of breast cancer cells. Environ Health Perspect. (2020) 128:27008. doi: 10.1289/EHP5862

98. Mervish N, McGovern KJ, Teitelbaum SL, Pinney SM, Windham GC, Biro FM, et al. Dietary predictors of urinary environmental biomarkers in young girls, BCERP, 2004-7. Environ Res. (2014) 133:12-9. doi: 10.1016/j.envres.2014.04.040

99. Gertz J, Reddy TE, Varley KE, Garabedian MJ, Myers RM. Genistein and bisphenol A exposure cause estrogen receptor 1 to bind thousands of sites in a cell type-specific manner. Genome Res. (2012) 22:2153-62. doi: 10.1101/gr.135681.111

100. Patterson AR, Mo X, Shapiro A, Wernke KE, Archer TK, Burd CJ. Sustained reprogramming of the estrogen response after chronic exposure to endocrine disruptors. Mol Endocrinol. (2015) 29:384-95. doi: 10.1210/me.2014-1237

101. Kang NH, Hwang KA, Lee HR, Choi DW, Choi KC. Resveratrol regulates the cell viability promoted by $17 \beta$-estradiol or bisphenol A via downregulation of the cross-talk between estrogen receptor $\alpha$ and insulin growth factor-1 receptor in BG-1 ovarian cancer cells. Food Chem Toxicol. (2013) 59:373-9. doi: 10.1016/j.fct.2013.06.029

102. Li X, Xie W, Xie C, Huang C, Zhu J, Liang Z, et al. Curcumin modulates miR-19/PTEN/AKT/p53 axis to suppress bisphenol Ainduced MCF-7 breast cancer cell proliferation. Phytother Res. (2014) 28:1553-60. doi: 10.1002/ptr.5167

103. Lee GA, Hwang KA, Choi KC. Inhibitory effects of 3,3'-diindolylmethane on epithelial-mesenchymal transition induced by endocrine disrupting chemicals in cellular and xenograft mouse models of breast cancer. Food Chem Toxicol. (2017) 109:284-95. doi: 10.1016/j.fct.2017.08.037

104. Lee GA, Choi KC, Hwang KA. Treatment with phytoestrogens reversed triclosan and Bisphenol A-induced anti-apoptosis in breast cancer cells. Biomol Ther. (2018) 26:503-11. doi: 10.4062/biomolther.2017.160

105. Bulzomi P, Bolli A, Galluzzo P, Acconcia F, Ascenzi P, Marino M. The naringenin-induced proapoptotic effect in breast cancer cell lines holds out against a high bisphenol a background. IUBMB Life. (2012) 64:690-6. doi: 10.1002/iub.1049

106. La Rosa P, Pellegrini M, Totta P, Acconcia F, Marino M. Xenoestrogens alter estrogen receptor (ER) a intracellular levels. PLoS ONE. (2014) 9:e88961. doi: 10.1371/journal.pone.0088961

107. Betancourt A, Mobley JA, Wang J, Jenkins S, Chen D, Kojima K, et al. Alterations in the rat serum proteome induced by prepubertal exposure to bisphenol a and genistein. J Proteome Res. (2014) 13:1502-14. doi: 10.1021/pr401027q

108. Dolinoy DC, Huang D, Jirtle RL. Maternal nutrient supplementation counteracts bisphenol A-induced DNA hypomethylation in early development. Proc Natl Acad Sci USA. (2007) 104:13056-61. doi: 10.1073/pnas.0703739104

109. Betancourt AM, Wang J, Jenkins S, Mobley J, Russo J, Lamartiniere CA. Altered carcinogenesis and proteome in mammary glands of rats after prepubertal exposures to the hormonally active chemicals bisphenol 
a and genistein. J Nutr. (2012) 142:1382s-8s. doi: 10.3945/jn.111. 152058

110. Jadhav RR, Santucci-Pereira J, Wang YV, Liu J, Nguyen TD, Wang J, et al. DNA methylation targets influenced by Bisphenol A and/or genistein are associated with survival outcomes in breast cancer patients. Genes. (2017) 8:144. doi: 10.3390/genes8050144

111. Brennan SF, Woodside JV, Lunny PM, Cardwell CR, Cantwell MM. Dietary fat and breast cancer mortality: a systematic review and meta-analysis. Crit Rev Food Sci Nutr. (2017) 57:1999-2008. doi: 10.1080/10408398.2012.724481

112. Leung YK, Govindarajah V, Cheong A, Veevers J, Song D, Gear $\mathrm{R}$, et al. Gestational high-fat diet and bisphenol A exposure heightens mammary cancer risk. Endocr Relat Cancer. (2017) 24:365-78. doi: 10.1530/ERC-17-0006

113. Rudel RA, Gray JM, Engel CL, Rawsthorne TW, Dodson RE, Ackerman JM, et al. Food packaging and bisphenol A and bis(2-ethyhexyl) phthalate exposure: findings from a dietary intervention. Environ Health Perspect. (2011) 119:914-20. doi: 10.1289/ehp.1003170
114. Wang J, Betancourt A, Jenkins S, Biro F, Pinney SM, Chen D, et al. Altered blood proteome in girls with high urine concentrations of bisphenol a, genistein, mono-ethyl hexylphthalate and mono-benzyl phthalate. MOJ Proteom Bioinform. (2015) 2:44-57. doi: 10.15406/mojpb.2015. 02.00040

Conflict of Interest: The authors declare that the research was conducted in the absence of any commercial or financial relationships that could be construed as a potential conflict of interest.

Copyright (C) 2020 Stillwater, Bull, Romagnolo, Neumayer, Donovan and Selmin. This is an open-access article distributed under the terms of the Creative Commons Attribution License (CC BY). The use, distribution or reproduction in other forums is permitted, provided the original author(s) and the copyright owner(s) are credited and that the original publication in this journal is cited, in accordance with accepted academic practice. No use, distribution or reproduction is permitted which does not comply with these terms. 